\title{
EDUCAÇÃO POPULAR: PROJETOS PEDAGÓGICOS PARA A EMANCIPAÇÃO
}

\author{
MARCELO CONCEIÇÃO DA ROCHA CAMPOS* \\ ELIANA DO SOCORRO DE BRITO PAIXÃO**
}

Resumo: este trabalho pretende analisar a criação e implementação de projetos pedagógicos que objetivam a manutenção da memória e difusão do pensamento de Paulo Freire, especificamente o projeto Cátedra Paulo Freire da Amazônia, como espaço privilegiado de ensino e pesquisa na busca pela recriação de práticas educativas, numa perspectiva de emancipação humana. Desse modo, intenta-se a investigação do seguinte problema: quais são as matrizes político-filosóficas que fundamentam o projeto Cátedra Paulo Freire da Amazônia, destacando seu processo de criação, objetivos e ações que podem favorecer a emancipação humana? O caminho metodológico delineado foi de uma pesquisa qualitativa, de natureza bibliográfica e documental, que possibilitou não só o debate acerca do método Paulo Freire, como também a compreensão dos pressupostos fundamentais do projeto Cátedra Paulo Freire, principalmente na Amazônia. Os resultados parciais mostram a importância e atualidade do pensamento de Paulo Freire, recriado e implementado por meio das cátedras.

Palavras-chave: Educação popular. Paulo Freire. Emancipação.

\section{Popular education: pedagogical projects for emancipation}

Abstract: this work intends to analyze the creation and implementation of pedagogical projects that aim at the maintenance and diffusion of Paulo Freire's memory and ideas, specifically the Paulo Freire Chair in the Amazon, as a privileged space of teaching and research in the search for educational practices reinvention, in a perspective of human emancipation. Thus, we try to investigate the following problem: what are the political-philosophical matrices that underlie the project Paulo Freire Chair of the Amazon, highlighting its process of creation, goals and actions that can favor human emancipation? The methodological approach outlined was a qualitative research, of a bibliographical and documentary nature, which made possible not only the debate about the Paulo Freire method, but also the understanding of Paulo Freire Chair Project's fundamental presuppositions, mainly in the Amazon. The partial results show the importance and relevance of Paulo Freire's thoughts and ideas, recreated and implemented through the chairs.

Key words: Popular education. Paulo Freire. Emancipation.

\section{Introdução}

O ingresso e permanência de grande parte da população no ensino primário só se verificou no Brasil a partir dos anos 1980-1990. Isso não foi resultado da falta de

\footnotetext{
* Licenciado em Letras e advogado. Mestrando em Educação - Universidade Federal do Amapá (UNIFAP). Professor de Língua Portuguesa e Literatura na rede pública estadual de ensino de Macapá/AP. E-mail: mcrcap@bol.com.br

** Doutora em Educação, docente do Programa de Pós-Graduação em Educação (UNIFAP) e do Curso de Secretariado Executivo (UNIFAP).E-mail: elianapaixao@unifap.br
} 
defensores da educação pública ou de medidas legais que determinassem a obrigatoriedade do ensino primário, uma vez que a ideia de expandir a educação já fora uma reivindicação dos primeiros republicanos (Carvalho, 2010).

O que ocorreu na prática, segundo a mesma autora, foi o fato de que o ensino primário sempre foi descurado, optando-se sempre que possível pelo barateamento e simplificação desse nível escolar, de forma que o Brasil chegou ao fim do século XIX sem conseguir atender a demanda da escolarização regular da população infantil e a educação de adultos foi feita de forma irregular e deficiente.

Recentemente, o último Censo Demográfico do Instituto Brasileiro de Geografia e Estatística (IBGE, 2010) apresentou um panorama nefasto para a educação no Brasil. Os dados apontam que mesmo com uma queda de quatro pontos percentuais em relação ao Censo 2000, a taxa de analfabetismo no País é hoje de $9,63 \%$, isto é, existem ainda 13,9 milhões de brasileiros - com 15 anos ou mais - analfabetos, dos quais a região Nordeste, mesmo com relativo crescimento econômico, permanece com maior número deles.

Diante de situações como essa, é preciso examinar criticamente esses dados, questionar e rever as práticas que podem ter conduzido a esse quadro negativo. Como aponta Pelandré (2002), os resultados tidos como mais positivos no que se refere a programas de alfabetização têm sido os dos programas de alfabetização desenvolvidos com base na concepção filosófica e epistemológica de Paulo Freire, que levam em conta a circunstância de vida dos educandos, tomando como objeto da prática pedagógica a sua cotidianidade.

De fato, com respaldo em Melo Neto (2008), tem-se no educador Paulo Freire, além da solidificação das bases da educação popular, a construção e implementação de programas de alfabetização que surgiram com as análises e críticas de situações existentes, em particular, ao analfabetismo, buscando a superação desse quadro com ações culturais para a liberdade. Essas ações libertadoras de Freire efetivaram programas junto a setores marginalizados - os oprimidos - visando à superação existencial da situação de dominado.

Dessa forma, este artigo pretende analisar a criação e implementação de projetos pedagógicos que objetivam a manutenção da memória e difusão do pensamento freireano, especificamente o projeto Cátedra Paulo Freire da Amazônia, como espaço 
privilegiado de ensino e pesquisa na busca pela recriação de práticas educativas, numa perspectiva de emancipação humana.

Assim, intenta-se a investigação do seguinte problema: quais são as matrizes político-filosóficas que fundamentam o projeto Cátedra Paulo Freire da Amazônia, destacando seu processo de criação, objetivos e ações que podem favorecer a emancipação humana? O caminho metodológico delineado foi de uma pesquisa qualitativa, de natureza bibliográfica e documental, que possibilitou não só o debate acerca do método Paulo Freire, como também a compreensão dos pressupostos fundamentais do projeto Cátedra Paulo Freire, principalmente na Amazônia.

A relevância deste trabalho se cristaliza não só como possibilidade de estudo do método de um personagem do passado, que teve sua valorosa contribuição inscrita nos campos sociais, políticos e pedagógicos, além da análise das bases políticofilosóficas do projeto das cátedras. Vai além: empenha-se em demonstrar a importância de um legado que atravessa fronteiras e tempos, permanecendo atual e universal.

\section{Método Paulo Freire: aspectos gerais}

A escolha do método deve preceder a atividade pedagógica de qualquer profissional que queira imergir na empreitada de alfabetizar, sob pena, caso contrário, de executar uma tarefa inócua. Essa escolha pode favorecer a aprendizagem e tende a obedecer diferentes situações, não sendo isenta de propósitos, já que cada método carrega uma dose de ideologia que repercute no pensamento e na prática de quem envereda pelo caminho da educação.

Figueirêdo (2008) registra que se vive diante de alguns paradoxos nesse novo milênio: ao mesmo tempo em que se avança no que se refere ao progresso tecnológico, a Humanidade caminha, por outro lado, num sentido quase inverso às capacidades de garantir um norte ético e emancipatório para a vida em coletividade. Logo, as múltiplas mudanças ensejam a construção de novos paradigmas educacionais.

Nesse quadro, o educador preocupado em encontrar alternativas para suplantar os problemas provocados por essas mudanças, pode encontrar na reflexão e análise da metodologia e no pensamento de Paulo Freire, respostas para as mais diversas indagações e inquietações que atravessam a prática pedagógica atualmente. Indubita- 
velmente, a educação popular de viés freireano ocupa uma posição de grande relevância no contexto da educação mundial, por incentivar a participação e o empoderamento das pessoas:

\begin{abstract}
A educação popular pode ser examinada como uma possibilidade educativa veiculada e incentivada tanto pelo Estado como por setores da sociedade civil - sindicatos, partidos políticos, organizações não-governamentais, igrejas e outras instituições. Tem despertado maior interesse como ferramenta de luta, a partir do início do século passado, na organização de setores das classes trabalhadoras. Manifestou-se no seio das práticas políticas dos anarquistas, sobretudo nas duas primeiras décadas, ou mesmo na perspectiva educacional do governo, desde a década de 30, estando presente na legislação ou em projetos da política governamental, voltados à educação do povo, compreendida como educação popular (Melo Neto, 2008, p. 15, grifo dos autores).
\end{abstract}

A educação popular, portanto, estimula o exercício da cidadania dos grupos populares, configurando-se como uma proposta contra-hegemônica incorporada às práticas decoloniais, com o objetivo de apresentar uma nova proposta educativa, fruto de grande inconformação da realidade social que privilegia alguns grupos em detrimento de outros. "[...] Entendo a educação popular como esforço de mobilização, organização e capacitação das classes populares; capacitação científica e técnica" (Freire; Nogueira, 1991, p. 19).

A educação popular, então, manifesta-se em contraposição a todas as práticas educacionais transmissivas, dando voz e vez aos indivíduos, empoderando-os a enfrentar as mais diversas formas de opressão e lutando por uma sociedade mais solidária e consciente de seus direitos. Gadotti (2012) apresenta a educação popular como representação dos movimentos sociais, sustentando a esperança, com suas múltiplas subjetividades políticas, na luta por direitos humanos e uma vida digna, pautando-se nas forças democráticas de poder local.

O exercício da docência, por Paulo Freire, na Universidade de Pernambuco, exerceu influência tanto na criação quanto no aprofundamento do método. O educador dizia que os métodos tradicionais, as velhas cartilhas, cujas lições repetiam mecanicamente que "Ivo viu a uva," não tinham relação com a alfabetização de adultos: 
[...] as palavras com que organizar o programa de alfabetização deveriam vir do universo vocabular dos grupos populares, expressando a sua real linguagem, os seus anseios, as suas inquietações, as suas reivindicações, os seus sonhos. Deveriam vir carregadas de significação de sua experiência existencial, e não da experiência do educador (Freire, 2006, p. 20).

Logo, o método nasce a partir da realidade do aluno, de modo que o primeiro passo é a descoberta do universo vocabular dos alunos, a fim de que as palavras estejam ligadas a suas experiências de vida (Freire, 1980). A partir disso, o conteúdo e a metodologia são selecionados para o trabalho, desenvolvendo a temática do contexto à palavra. A finalidade desse primeiro passo é alfabetizar os educandos a partir de sua realidade social, além de familiarizá-los com a leitura, capacitando-os para ler e interpretar o mundo.

O conhecimento desse contexto vocabular do aluno permite o surgimento das palavras geradoras. De acordo com Brandão (1981), é a partir de tais palavras que o aluno descobre as pistas para a construção do conhecimento, e então é passado para a fase do aprendizado em grupo diante da realidade social em que se vive. $O$ desvelamento dessas palavras geradoras ocorre no círculo de cultura, o qual simboliza:

[...] a formação em grupo dos alfabetizandos para que, dessa forma, possam realizar a construção do conhecimento mediante a troca de experiências, no qual o professor vai sondando o educando para que possa ir além do seu saber. A metodologia nessa linha torna possível a abordagem de temas interdisciplinares como, por exemplo, a palavra geradora 'eleição', que permite desabrochar no círculo de cultura os problemas de educação, trabalho, etc. (Silva; Nunes, 2016, p. 54).

Há no decurso dessa prática, a construção do processo de alfabetização por meio do vínculo dialético, no qual o animador cultural ${ }^{1}$ vai indagando os estudantes para o surgimento de novas palavras, pela discussão de palavras geradoras de caráter político-social, ilustradas com slides que representavam os temas. Carvalho (2010, p. 40) assinala que "essas palavras-chave eram então desmembradas em sílabas, que davam origem às famílias silábicas; das combinações de sílabas, surgiam novas palavras".

\footnotetext{
${ }^{1}$ Quase sempre era um jovem estudante secundarista ou universitário a quem competia coordenar a discussão, jamais influir ou impor (Carvalho, 2010). No lugar do professor, o que havia era o animador cultural.
} 
Na obra Educação como prática da liberdade (1967), Paulo Freire apresenta a proposta de execução de seu método dividido em cinco fases, quais sejam: levantamento do universo vocabular dos grupos; escolha das palavras selecionadas do universo vocabular pesquisado; criação de situações existenciais típicas do grupo com quem se vai trabalhar; elaboração de fichas-roteiro e feitura de fichas com a decomposição das famílias fonêmicas correspondentes aos vocábulos geradores.

O levantamento do universo vocabular dos grupos - primeira fase - é realizado por meio de encontros informais, nos quais se fixam as palavras com maior sentido existencial e emocional para os envolvidos, suas expressões particulares e vocábulos ligados à experiência dos grupos (Freire, 1967). Já a escolha das palavras selecionadas do universo vocabular pesquisado - segunda fase - obedece a três critérios, segundo o autor: o da riqueza fonêmica, o das dificuldades fonéticas e o de teor pragmático da palavra, implicando numa maior pluralidade de engajamento da palavra numa dada realidade.

A terceira fase, representada pela criação de situações existenciais típicas do grupo com quem se vai trabalhar, consiste em situações desafiadoras "codificadas, guardando em si elementos que serão descodificados pelos grupos, com a colaboração do coordenador" (Freire, 1967, p. 113). Trata-se de situações que possibilitam a análise de problemas regionais e nacionais.

Já na quarta fase - elaboração de fichas-roteiro - tem-se um subsídio para os coordenadores utilizarem na condução dos debates que jamais poderá ser uma prescrição rígida a qual devam obedecer e seguir. Por fim, através da feitura de fichas com a decomposição das famílias fonêmicas correspondentes aos vocábulos geradores, confeccionadas em slides, stripp-filmes ou cartazes pelas equipes de coordenadores e supervisores, pode-se se iniciar o trabalho.

A proposta apresentada pelo método Paulo Freire tinha um cunho absolutamente inovador, uma vez que valorizava a cultura e a oralidade das pessoas, possibilitando uma aprendizagem libertadora, horizontal, já que, conforme Freire (1967, p. 110), "a alfabetização não pode ser feita de cima para baixo, como uma doação ou uma imposição, mas de dentro para fora, pelo próprio analfabeto, apenas com a colaboração do educador". 


\section{A Categoria Emancipação na Obra de Paulo Freire}

Aspecto importante na construção deste estudo é a busca por um entendimento melhor da categoria emancipação à luz da visão freireana. Certamente, não há o propósito de esgotar todos os seus aspectos, envolvendo significados, panorama histórico, tampouco se intenta tecer uma profunda abordagem da etimologia do termo. 0 intuito é de desvelar os sentidos subjacentes ao termo emancipação, com arrimo na perspectiva de Paulo Freire.

Uma rápida consulta ao Dicionário Michaelis da Língua Portuguesa (2018) permite inferir que o vocábulo emancipação é polissêmico, posto que possui amplo espectro de significações. Assim, pode indicar: "1 Ação ou efeito de emancipar(-se). 2 Movimento de libertação; alforria, independência. 3 Jur Instituto jurídico brasileiro que proporciona direitos civis à pessoa maior de 18 e menor de 21 anos".

O conceito provém do Latim emancipare, que se refere ao processo de considerar indivíduos ou grupos de indivíduos independentes e representa o processo histórico, ideológico e formativo de emancipar pessoas, grupos sociais e países da tutela política, econômica, cultural ou ideológica (Pizzi, 2005). Nessa acepção, emancipar-se pressupõe o exercício de noções como autonomia, liberdade, desalienação, sendo possível, assim, no contexto de sociedades democráticas.

Adorno (2006) ressalta a importância de um tratamento mais cauteloso no uso da palavra emancipação, de maneira a fugir da aplicação despreocupada, da simplória "retórica", por demandar um exame mais pormenorizado, implicando na necessidade de perceber as enormes dificuldades que se opõem à emancipação neste mundo. Assim, resta imprescindível uma análise mais específica do termo, a fim de aprofundar a compreensão dessa categoria.

No afã de uma referência teórica mais específica concernente à categoria emancipação, chega-se a Paulo Freire, tal como mencionado por Figueirêdo (2008, p. 68):

Paulo Freire tem um papel importante na feitura dos diversos constituintes que compõem o campo de intervenção da educação popular emergente no Brasil e na América Latina desde os anos 60. Portanto, é fundamental refletir as contribuições desse educador brasileiro no 
debate sobre o projeto de emancipação que permeia as práticas da educação popular. Emancipação na perspectiva de Freire é apropriarse e experimentar o poder de pronunciar o mundo, a vivência da condição humana de ser protagonista de sua história. Freire nos possibilita um projeto de educação popular que almeja a libertação, humanização e emancipação humana.

Figueiredo (2008) prossegue, indicando que não se identifica nas obras de Paulo Freire, a exemplo de Pedagogia do oprimido, Educação como prática de liberdade, Pedagogia da esperança, Pedagogia da autonomia, um conceito específico, um aprofundamento acerca do termo emancipação. O que há é um movimento teórico e prático em desfavor da opressão, da desumanização e pela libertação humana. Nesse sentido, Freire se refere à emancipação como processo de libertação, humanização dos seres humanos, conclui a autora.

Freire, no livro Pedagogia do oprimido, proclama uma pedagogia destinada a todos, a fim de que a totalidade dos indivíduos possa se emancipar, por meio de uma batalha libertadora que somente faz sentido se os oprimidos, buscando sua humanidade, não se sintam opressores, e sim restauradores da Humanidade, no sentido de libertar a si e os opressores (Freire, 2005). Ele acredita que os oprimidos são plenamente capazes de se libertarem do contexto de opressão, ao despertarem para essa situação de injustiça.

Antes de serem plenamente livres, os seres humanos, sejam eles oprimidos ou opressores, são reféns da desumanização. Daí, então, que surge a pedagogia do oprimido, que não pode ser construída nem praticada pelos opressores, na condição de pedagogia daqueles que estão empenhados na busca de sua libertação, de sua humanidade. Deverá ser ela, então, a "pedagogia que faça da opressão e de suas causas objeto da reflexão dos oprimidos, de que resultará o seu engajamento necessário na sua libertação, em que esta pedagogia se fará e refará" (Freire, 2005, p. 34).

Conforme Figueirêdo (2008, p. 70), Paulo Freire se revela como um defensor intransigente da emancipação humana. Contudo, ele admite os limites da concretização de uma sociedade emancipada no cenário do Capitalismo, "por isso Freire reflete o processo de libertação (emancipação) como projeto de sociedade, como possibilidade, um devenir, que se inicia em casa, nas relações entre pais, mães, filhos, filhas, na escola, nas relações de trabalho". 
A libertação (emancipação), assim, não ocorrerá como obra do acaso, como mera eventualidade; ela acontecerá com base no engajamento na luta por ela, por meio da práxis de sua busca. É nesse sentido que Freire $(2005$, p. 38) assevera que "a libertação, por isto, é um parto. E um parto doloroso. O homem que nasce desse parto é um homem novo que só é viável na e pela superação da contradição opressoresoprimidos, que é a libertação de todos".

Desse modo, a proposta de educação em Paulo Freire se pauta no compromisso com a efetivação da emancipação político-cultural e social dos indivíduos, para que, então, possam petrificar a sua humanização. Esse processo perpassa pela educação, de maneira que ao educador crítico cabe a tarefa de contribuir com o despertar da consciência, nos indivíduos, da necessidade de emancipação, para que assumam o compromisso da transformação da realidade.

\section{Projetos Pedagógicos para a Emancipação}

Paulo Freire já advertia as pessoas interessadas na implementação de seus pressupostos no que diz respeito à continuidade de seu legado. Afirmação presente no excerto a seguir:

Quanto aos outros, os que põem em prática a minha prática, que se esforcem por recriá-la, repensando também meu pensamento. E ao fazê-lo, que tenham em mente que nenhuma prática educativa se dá no ar, mas num contexto concreto, histórico, social, cultural, econômico, político, não necessariamente idêntico. (Freire, 1981, p. 17).

Imbuídas dessa tentativa de reinventar a obra de Paulo Freire, efetuando uma releitura crítica de seus trabalhos, é que surgiram iniciativas espalhadas pelo País. Uma delas é o projeto Cátedra Paulo Freire. Considerando que ele foi professor da PUC/SP, no Programa de Educação: Currículo, após seu retorno do exílio, pelo período de 17 anos (1980 -1997), foi criada em sua homenagem, no 2o semestre de 1998 - logo depois de seu falecimento - a Cátedra Paulo Freire da PUC/SP, pioneira no Brasil:

A Cátedra vem sendo compreendida para além de um lugar de homenagem a uma personalidade. Na PUC/SP, em particular neste Programa, temos entendido a Cátedra como um espaço especial para o desenvolvimento de estudos e pesquisas sobre/e a partir da obra de 
Paulo Freire, focalizando as suas repercussões teóricas e práticas para a educação e a sua potencialidade de fecundar novos pensamentos. Em outras palavras, homenageamos Paulo Freire, do jeito que entendemos que ele gostaria de ser homenageado, estudando com rigorosidade o seu pensamento, para compreendê-lo e para recriá-lo (Saul, 2006, p. 2).

Saul (2012) registra que a Cátedra Paulo Freire - PUC/SP desenvolve uma metodologia que contempla "múltiplos itinerários", ou seja, diversos focos de trabalho são desenvolvidos concomitantemente, conforme o interesse e objeto de investigação dos alunos, referenciados na pedagogia freireana. O percurso da metodologia, segundo a mesma autora, contempla alguns momentos, quais sejam investigação temática imersão no pensamento freireano, socialização e discussão na classe, mapeamento dos conceitos do grupo e aprofundamento dos conceitos de cada subgrupo formado na classe.

Atualmente, a Cátedra desenvolve uma pesquisa sobre a influência do pensamento e da obra de Paulo Freire nos sistemas públicos de ensino no Brasil, com o fito de contribuir para a recriação de políticas e práticas educativas numa perspectiva crítico-emancipadora (Saul, 2012). Os objetivos dessa pesquisa são, dentre outros, consoante esse autor (Saul, 2012), subsidiar o fazer "político-pedagógico" das redes públicas de ensino, identificar e analisar a influência de Paulo Freire nos sistemas públicos de ensino do Brasil, articular pesquisadores e pós-graduandos de várias regiões do País e do Exterior que investigam a influência de Freire na educação e divulgar os resultados.

Essa rede de estudiosos e pesquisadores do legado freireano - as cátedras - logo se espalhou pelo País. Atualmente, outro exemplo importante desses espaços de socialização do pensamento do patrono da educação foi gestado na Universidade Federal de Pernambuco no ano de 2005, e instalada em 4 de maio de 2009, por meio da criação da Cátedra Paulo Freire/UFPE, que se justifica em três razões, consoante assinalam Santiago, Batista Neto e Guedes (2016): reconhecimento institucional, preservação da memória e espaço de produção e socialização da Pedagogia Paulo Freire.

Trata-se de um espaço de estudos articulados em três eixos temáticos, quais sejam extensão e socialização do pensamento freireano, estudo da pedagogia freireana e produção de conhecimento. Além de representar uma homenagem a um exprofessor daquela universidade, a Cátedra Paulo Freire/UFPE demonstra o reconheci- 
mento da comunidade acadêmica ao patrimônio pedagógico e social deixado por Paulo Freire ao Mundo, tomando como base a educação (Santiago; Batista Neto; Guedes, 2016).

No ano de 2016, com a finalidade de desenvolver atividades de pesquisa, formação, intervenção, publicações, eventos, dentre outras, com fundamento no legado de Paulo Freire. foi criada a Cátedra Paulo Freire da Amazônia, congregando pesquisadores, educadores, militantes do Pará, Amapá e Amazonas que se pautam no legado de Paulo Freire. Seus objetivos estão claramente definidos, em documento elaborado no âmbito da Universidade do Estado do Pará (UEPA, 2016, p. 7):

Promover estudos sobre o pensamento e o legado de Paulo Freire, proporcionando releituras de suas obras, bem como o aprofundamento de conceitos freireanos, temáticas e teorias educacionais; Realizar pesquisas sobre práticas educativas em diferentes contextos sociais e educacionais, que tenham como referência o legado de Paulo Freire; Promover a socialização de estudos de Paulo Freire na Amazônia por meio de publicações e eventos; Viabilizar intercâmbios locais, regionais, nacionais e internacionais com grupos e redes de pesquisas, fóruns e movimentos sociais que estudam e desenvolvem atividades educativas com o legado freireano; Fomentar a produção do conhecimento em educação popular na Amazônia, em articulação com grupos de pesquisa, programas de pós-graduação, movimentos sociais, escolas públicas, fóruns, populações do campo, indígena, quilombolas e negras, das águas, da floresta, entidades da sociedade civil e secretarias municipais e estaduais de educação; Incentivar a realização de intervenções educativas e de formação de educadores populares e professores das redes públicas de ensino, referenciados pelas práxis freireana.

No plano das ações daquilo que se deseja implementar, a referida Cátedra propõe a realização de estudos e pesquisas em rede; publicação de livros e criação de um periódico; promoção de eventos e intercâmbios; formação de professores; e criação de um banco de dados com produções freireana. Tal iniciativa tem a finalidade de preservar o legado da educação de Paulo Freire, ponderando acerca da sua educação no contexto socioeducacional e cultural da Amazônia (UEPA, 2016).

A Cátedra Amazônida Paulo Freire, coordenada pela Prof. Drá. Ivanilde Apoluceno de Oliveira, vincula diversos grupos de pesquisa da Região, tais como Núcleo de Educação Popular Paulo Freire (NEP), Grupo Saberes e Práticas Educativas de Populações Quilombolas (EDUQ), Grupo de Estudo e Pesquisa em Desenvolvimento, Educa- 
ção e Trabalho na Amazônia (GEPDETAM) e Grupo de Estudos Indígenas da Amazônia (GEIA).

Conforme dados consultados em UEPA (2016), a mencionada Cátedra é coordenada pelo Núcleo de Educação Popular Paulo Freire - NEP/UEPA e congrega as seguintes instituições: a própria UEPA; Universidade Federal do Pará (UFPA); Instituto Federal do Pará (IFPA); Universidade Federal do Amapá (UNIFAP); Universidade do Estado do Amazonas (UEA); Universidade Federal do Amazonas (UFAM); Instituto Universidade Popular (UNIPOP).

Pode-se depreender que a interação estabelecida entre essa multiplicidade de instituições, consumada na troca de experiências entre inúmeros pesquisadores, irá incentivar a leitura e a pesquisa acerca da educação popular freireana. Dessa maneira, torna-se possível a intervenção e a execução de práticas educativas de cunho libertador nos mais diferentes espaços sociais e educacionais amazônidas por indivíduos inspirados nos ideais freireanos.

Com o intuito de promover o fortalecimento das ações da Cátedra no contexto amapaense, teve início o "Ciclo de Estudos Paulo Freire e a Educação Amazônida," na segunda quinzena de setembro de 2016. Em seguida, no dia 23 de setembro de 2016, aconteceu uma reunião com representantes do Sindicado dos Servidores Públicos Federais Civis no Estado do Amapá (SINDSEP-AP), grupos de pesquisa da UNIFAP, UEAP e com a Rede de Educação Cidadã do Amapá (RECID-AP) que gestou a Cátedra Paulo Freire da Amazônia Amapaense.

A cátedra, em âmbito local, nasce a partir do projeto de pesquisa Paulo Freire e a Educação Popular da Amazônia Amapaense: História e Memória de Experiências Educativas, coordenado pelo Professor Alder de Sousa Dias. Esse projeto agrega os grupos de pesquisa GISAE-UEAP ${ }^{2}$, GEPEA-UEAP ${ }^{3}$, GEPEIF-UFPA ${ }^{4}$, GEFOR-UNIFAP ${ }^{5}$, GPEGUFPA $^{6}$, NEDHEL-UFMA $^{7}$, Amazônia Sustentável (UNIFAP), e tem a clara intenção de consolidar e robustecer, no âmbito amapaense, os objetivos da Cátedra Paulo Freire da Amazônia, além de se configurar como uma representação local do Projeto:

\footnotetext{
${ }^{2}$ Grupo de Integração Socioambiental e Educacional.

${ }^{3}$ Grupo de Estudos, Pesquisas e Práticas em Educação na Amazônia Amapaense.

${ }^{4}$ Grupo de Estudos e Pesquisas em Educação, Infância e Filosofia.

${ }^{5}$ Grupo de Pesquisa em Educação, Trabalho e Formação Humana.

${ }^{6}$ Grupo de Pesquisa em Ensino de Geografia nos Países Subdesenvolvidos.

${ }^{7}$ Núcleo de Estudos e Documentação em História da Educação e das Práticas Leitoras no Maranhão.
} 
Uma das relevâncias deste projeto para a construção do conhecimento científico sobre o legado praxiológico de Paulo Freire consiste no fato de se buscar registrar, analisar e sistematizar dados de três experiências educativas que se notabilizaram por ter como uma de suas bases o pensamento educacional freireano, são elas: o "Curso de Educação Profissional em Produtos da Floresta, Práticas Culturais Amazônicas e Práticas Ocupacionais Urbanas, com elevação da Escolaridade ao Ensino Fundamental"; a construção da proposta de educação para os povos da floresta do CNS; e a proposta de escola pública popular para o sistema de educação do Estado do Amapá (UNIFAP, 2017, p. 11).

Há a intenção, pelo que se observa a partir da criação das Cátedras, em especial a da Amazônia, de propiciar o entendimento da obra de Paulo Freire e das questões metodológicas constantes em seu pensamento, a fim de aprofundar categorias pedagógicas debatidas por esse educador e colocar em prática, seja em qual for o ambiente, suas concepções e contribuições no campo da educação.

Por meio da pesquisa, troca de informações e divulgação de experiências de estudiosos do pensamento freireano na região amazônica, consumada na Cátedra, evidenciam-se importantes aspectos. Trata-se da possibilidade e da finalidade de implementação de uma prática pedagógica que respeite o conhecimento dos educandos, que privilegie o diálogo e que possibilite a construção coletiva do conhecimento, numa perspectiva crítico-emancipadora.

Além disso, é possível vislumbrar no cenário amazônico, com a Cátedra Paulo Freire, o estabelecimento de "elos" - entre pesquisadores, instituições, movimentos que permitirão não só a análise e o aprofundamento das ideias freireanas, como também a constituição de referenciais que podem servir de aporte para o engendramento de políticas públicas educacionais que respeitem as particularidades de cada lugar.

A articulação entre investigadores dos Estados da Amazônia que se ocupam de pesquisar a influência de Paulo Freire na educação, com o fito de estudar e divulgar sua obra, permitirá, ademais, a compreensão do alcance de suas ideias nos projetos educativos executados na região. Além disso, trata-se de observar a atualidade do pensamento freireano no contexto social e educacional, possibilitando a construção de um projeto educativo libertador e verdadeiramente significativo para o projeto de vida dos oprimidos do espaço amazônico. 


\section{Considerações Finais}

Ao se deparar com uma realidade educacional que se apresenta de maneira opressora e alienante é necessário denunciá-la e buscar mecanismos para reverter esse quadro. Nesse sentido, a educação popular se configura como uma prática que, independentemente dos espaços onde possa ser realizada (sejam eles públicos, alternativos, governamentais, ou não formais) pode, através de uma metodologia que incentiva a participação social e a emancipação humana, fortalecer condições de apreensão e leitura crítica da realidade, de maneira a estimular os agentes envolvidos a transformála.

Obviamente que, além de uma sólida organização dos oprimidos com o objetivo de se libertarem - já que não se trata de autolibertação, ou seja, ninguém se liberta sozinho e sim em comunhão -, e de mudarem a realidade posta, há o imperativo de que os indivíduos se engajem de forma plena nessa batalha, razão pela qual é preciso que eles estejam convencidos da necessidade de participar ativamente do processo de mudança e se insiram criticamente na situação.

Nesse sentido, a educação popular pode auxiliar no processo de compreensão crítica da realidade, estimulando a emancipação da situação de opressão que torna os indivíduos reféns e subsidiando o autodesenvolvimento da população. No seio da educação popular libertadora, entende-se esta experiência como uma prática, mas ao mesmo tempo um processo de luta, que busca, por meio do empoderamento e emancipação das massas, romper com a divisão de classes.

Até hoje, continuam vivos os paradigmas fundamentais do pensamento de Paulo Freire, fazendo de suas ideias um tema atual e recorrente, sobretudo na defesa de uma educação para a liberdade, pautada no diálogo e na recusa do autoritarismo, e que valorize o cotidiano dos educandos. O legado desse pensador, baseado numa concepção de educação popular, colabora para a construção de matrizes pedagógicas contemporâneas que reafirmam suas concepções, ratificando a atualidade de seu pensamento.

No bojo das tentativas de recriação dos referenciais freireanos, a Cátedra Paulo Freire na Amazônia se cristaliza como um coletivo de agentes humanos, com experiências e caminhadas diferentes, aproximados pelos objetivos de manter vivo o legado de 
Paulo Freire e de somar com a tentativa de construir uma educação crítica e dialógica. Não se pode olvidar, desse modo, que a educação popular propalada e defendida por esses espaços de discussão, pode caminhar para a superação dos modos existentes de opressão, pode ser uma pedagogia emancipatória.

\section{Referências}

ADORNO, Theodoro W. Educação e emancipação. Rio de Janeiro: Paz e Terra, 2006. BRASIL. Instituto Brasileiro de Geografia e Estatística (IBGE). Censo demográfico 2010 resultado do universo. Rio de Janeiro, 2011. 1 CD ROM.

CARVALHO, Marlene. Primeiras Letras: Alfabetização de Jovens e Adultos em espaços populares. São Paulo: Ática, 2010.

FIGUEIRÊDO, Maria do Amparo Caetano de. Emancipação humana e a educação popular: um devenir. In: ROSAS, Agostinho da Silva; MELO NETO, José Francisco de (Org.). Educação popular: enunciados teóricos. v. 2. João Pessoa: UFPB, 2008.

FREIRE, Paulo. Educação como prática da liberdade. Rio de Janeiro: Paz e Terra, 1967. . Conscientização: teoria e prática de libertação - uma introdução ao pensamento de Paulo Freire. 3. ed. São Paulo: Moraes, 1980.

; NOGUEIRA, Adriano. Que fazer: teoria e prática em educação popular. 3. ed. Petrópolis: Vozes, 1991.

; Pedagogia do oprimido. Rio de Janeiro: Paz e Terra, 2005.

. A importância do ato de ler. 48. ed. São Paulo: Cortez, 2006.

GADOTTI, Moacir. Educação popular, educação social, educação comunitária: conceitos e práticas diversas, cimentadas por uma causa comum. Revista diálogos, Brasília, 2012.

MELO NETO, José Francisco de. Educação popular: sistema de teorias intercomunicantes. In: ROSAS, Agostinho da Silva; MELO NETO, José Francisco de (Org.). Educação popular: enunciados teóricos. v. 2. João Pessoa: UFPB, 2008.

MICHAELIS, Dicionário. Dicionário da Língua Portuguesa. Disponível em: $<$ http://michaelis.uol.com.br/>. Acesso em: 1 fev. 2018.

PIZZI, Jovino. O desenvolvimento e suas exigências morais. Disponível em: <http:// www.ucpel.tche.br/filosofia/vol1/desenvolvimento. pdf>. Acesso em: 1 fev. 2018.

SANTIAGO, Eliete; BATISTA NETO, José; GUEDES, Marília Gabriela. A Cátedra Paulo Freire da Universidade Federal de Pernambuco: memória e atualidades tecidas a várias mãos. Disponível em: <http://coloquio.paulofreire.org.br/participacao/index.php/colo quio/ix-coloquio/paper/view/782>. Acesso em: 1 fev. 2018,

SAUL, Ana Maria. A Cátedra Paulo Freire da PUC/SP. Revista E-Curriculum, v. 1, n. 2, jun. 2006. ISSN 1809-3876.

. Ensinando e pesquisando na Cátedra Paulo Freire da PUC/SP. Anais do XVI ENDIPE - Encontro Nacional de Didática e Práticas de Ensino - UNICAMP/Campinas. 2012.

SILVA, Simone C. Rodrigues da; NUNES, Maria Alice Melo. Um olhar sobre o Método Paulo Freire na Educação de Jovens e Adultos. Revista Com Censo. 2. ed., n. 5, maio 2016.

UNIVERSIDADE DO ESTADO DO PARÁ. Projeto de Criação da Cátedra Paulo Freire da 
Amazônia. Belém: UEPA/CCSE/NEP, 2016. (Formato Digital).

UNIVERSIDADE FEDERAL DO AMAPÁ. Projeto Paulo Freire e a educação popular da Amazônia amapaense: história e memória de experiências educativas. Macapá: UNIFAP, 2017. (Formato Digital).

Artigo recebido em setembro de 2018 e aceito em novembro de 2018. 